\title{
PENGARUH NESTING TERHADAP PERUBAHAN FISIOLOGIS BAYI PREMATUR DI RUANG PERINATOLOGI RSUD DR. M. YUNUS BENGKULU
}

\author{
Yeni Eliyanti ${ }^{1}$,Nasaratri Hasta Noeraini ${ }^{2)}$ \\ ${ }^{1,2}$ Program Profesi Ners, Program Studi Kesehatan Masyarakat STIKES Bhakti Husada \\ Bengkulu, Bengkulu \\ E-mail: yenieliyanti@yahoo.co.id
}

\begin{abstract}
Problems:One form of nursing intervention besides the kangaroo method that can be done on BBLR is nesting. Nesting is used to give the neonate the right position. The Aim Of The Research:The research objective was to determine the effect of nesting on physiological changes in premature infants in the perinatology room of RSUD DR. M. Yunus Bengkulu. Research Method: The research design used quasi-experimental design with a nonequidment control group design with one intervention group and one control group.The Results:The results showed that the average oxygen saturation in the control group was 96.22, while in the intervention group was 98.17 at the Perinatology Room of dr. M. Yunus Bengkulu. The average frequency of respiratory in the control group was 85.44 while in the intervention group it was found that the average respiratory frequency was 97.61 at the Perinatology Room of RSUD dr. M. Yunus Bengkulu. The average pulse frequency in the control group was 97.44 while in the intervention group it was found that the average pulse frequency was 110.50 at the Perinatology Room of RSUD dr. M. Yunus Bengkulu. Conclusions:There was a nesting effect on oxygen saturation in premature infants at the Perinatology Room of RSUD DR. M. Yunus Bengkulu with $p$ value 0.007 . There was a nesting effect on the frequency of respiratory in premature infants in the Perinatology Room of DR. M. Yunus Bengkulu with a $\mathrm{p}$ value of 0.003 and there was a nesting effect on pulse frequency in premature babies in the Perinatology Room of RSUD DR. M. Yunus Bengkulu with $\mathrm{p}$ value 0.047.
\end{abstract}

Keywords: Nesting, Oxygen Saturation, Respiratory Frequency, Pulse Frequency, Premature Infants.

\begin{abstract}
ABSTRAK
Permasalahan:Salah satu bentuk intervensi keperawatan selain metode kanguru yang dapat dilakukan pada BBLR adalah nesting. Nesting digunakan untuk memberikan posisi yang tepat pada neonatus. Tujuan Penelitian:Mengetahui pengaruh nesting terhadap perubahan fisiologis bayi premature di Ruang perinatology RSUD DR. M. Yunus Bengkulu.Metode Penelitian:Rancangan penelitian yang digunakan adalah quasi eksperiment dengan rancangan non equidment control group design dengan satu kelompok intervensi dan satu kelompok kontrol.Hasil:Hasil penelitian di dapatkan Rata-rata saturasi oksigen pada kelompok kontrol adalah 96,22 sedangkan pada kelompok intervensi didapatkan rata-rata saturasi oksigen adalah 98,17 di Ruang Perinatologi RSUD dr. M. Yunus Bengkulu. Rata-rata frekuensi nafas pada kelompok kontrol adalah 85,44sedangkan pada kelompok intervensi didapatkan rata-rata frekuensi nafas adalah 97,61 di Ruang Perinatologi RSUD dr. M. Yunus Bengkulu. Rata-rata frekuensi nadi pada kelompok kontrol adalah 97,44 sedangkan pada kelompok intervensi didapatkan rata-rata frekuensi nadi adalah 110,50 di Ruang Perinatologi RSUD dr. M. Yunus Bengkulu. Kesimpulan:Ada pengaruh nesting terhadap saturasi oksigen pada bayi prematur di Ruang Perinatologi RSUD DR. M. Yunus Bengkulu dengan $p$ value 0,007. Ada pengaruh nesting terhadap frekuensi nafas pada bayi prematur di Ruang Perinatologi RSUD DR. M. Yunus Bengkulu dengan $p$ value 0,003 dan ada pengaruh nesting terhadap frekuensi nadi pada bayi prematur di Ruang Perinatologi RSUD DR. M. Yunus Bengkulu dengan $p$ value 0,047 .
\end{abstract}

Kata Kunci :Nesting, Saturasi Oksigen, Frekuensi Nafas, Frekuensi Nadi, Bayi Prematur 


\section{PENDAHULUAN}

Prematuritas berhubungan dengan morbiditas dan mortalitas balita. Kelahiran prematur merupakan salah satu penyumbang terbesar pada kematian perinatal dan kesakitan neonatus, baik jangka pendek maupun jangka panjang (Sulistiarini \& Berliana, 2016). WHO (2012) menyatakan prematuritas merupakan penyebab kematian kedua pada balita setelah pneumonia dan merupakan penyebab utama kematian neonatal. Tiga puluh lima persen kematian neonatal di dunia disebabkan oleh komplikasi kelahiran prematur. Jumlah kematian neonatal dengan usia 0-6 hari sebesar 78,5\%. Proporsi terbesar disebabkan oleh gangguan atau kelainan pernafasan (respiratory disorders), selanjutnya urutan kedua oleh prematuritas dan ketiga disebabkan oleh sepsis.

Bayi prematur merupakan bayi yang lahir dengan usia kehamilan < 32 minggu, mempunyai risiko kematian 70 kali lebih tinggi, karena mereka mempunyai kesulitan untuk beradaptasi dengan kehidupan di luar rahim akibat ketidak matangan sistem organ tubuhnya seperti paruparu, jantung, ginjal, hati dan sistem pencernaannya, sekitar $75 \%$ kematian perinatal disebabkan oleh prematuritas (Krisnadi dkk, 2009).

Angka kejadian persalinan prematur pada umumnya adalah sekitar $6-10 \%$. Hanya $1,5 \%$ persalinan terjadi pada umur kehamilan kurang dari 32 minggu dan $0,5 \%$ pada kehamilan kurang dari 28 minggu. Namun kelompok ini merupakan duapertiga dari kematian neonatal. Kesulitan utama dalam persalinan prematur ialah perawatan bayi prematur, yang semakin muda usia kehamilannya semakin besar morbiditas dan mortalitas (Prawiroharjo S, 2012).

Angka kematian bayi dan balita untuk periode lima tahun sebelum survey masingmasing adalah 32 dan 40 kematian per 1.000 kelahiran hidup. Berarti satu di antara 31 bayi meninggal sebelum mencapai umur satu tahun, dan satu di antara 28 anak meninggal sebelum mencapai ulang tahun kelima, $60 \%$ kematian bayi terjadi pada umur 0 bulan (SDKI, 2012).

Berbagai upaya dilakukan untuk menurunkan Angka Kematian Bayi dan meminimalkan dampak negatif yang ditimbulkan selama perawatan. Upaya tersebut dilakukan agar BBLR berada dalam kondisi yang optimal untuk tumbuh dan berkembang yaitu kondisi seperti di dalam rahim. Salah satunya yaitu dengan menerapkan developmental care atau asuhan perkembangan. Developmental care ialah perawatan yang dilakukan pada bayi khususnya untuk meningkatkan pertumbuhan dan perkembangan bayi yang dirawat di rumah sakit (Aita \& Snider, 2003 ). 
Prinsip-prinsip developmental care meliputi keterlibatan keluarga, posisi dan nesting, perawatan kulit, meminimalkan stres dan nyeri, mengoptimalkan nutrisi, dan meningkatkan kualitas tidur (Altimier, 2011). Tindakan yang dapat mendukung tujuan tersebut di atas diantaranya dengan memberikan cahaya yang redup, suara yang rendah, kehangatan, sentuhan lembut, kontrol nyeri, lampin dan nesting(Bayuningsih, 2011).

Nesting adalah suatu alat yang digunakan di ruang perinatologi terbuat dari bahan phlanyl dengan panjang sekitar $121 \mathrm{~cm}-132 \mathrm{~cm}$, dapat disesuaikan dengan panjang badan bayi yang diberikan pada bayi prematur/BBLR. Nesting ditujukan untuk meminimalkan pergerakan neonatus sebagai salah satu bentuk konversi energi yang merupakan salah satu bentuk intervensi keperawatan. Pemasangan nesting atau sarang serta posisi fleksi pada bayi juga merupakan bentuk pengelolaan lingkungan dalam development care. Nesting dapat menopang tubuh bayi dam memberi tempat yang nyaman (Andhini, 2017).

Tujuan Penelitianadalah mengetahui pengaruh nesting terhadap perubahan fisiologis bayi premature di Ruang perinatology RSUD DR. M. Yunus Bengkulu.

\section{METODE PENELITIAN}

Rancangan penelitian yang digunakan adalah quasi eksperiment dengan rancangan non equidment control group design dengan satu kelompok intervensi dan satu kelompok kontrol (Notoatmodjo, 2014).Populasi pada penelitian ini adalah bayi prematur yang dirawat di ruang Perinatologi RSUD Dr. M. Yunus Bengkulu. Sampel pada penelitian ini menggunakan metode non probability sampling dengan teknik pengambilan data menggunakanpurposive sampling adalah suatu metode pemilihan sampel yang dilakukan berdasarkan maksud dan tujuan tertentu yang ditenukan peneliti (Dharma, 2011). Penelitian sebelumnya yang dilakukan oleh(Bayuningsih, 2011), meneliti tentang nestingdan posisi prone terhadap saturasi oksigen dan frekuensi nadi pada bayi prematur didapatkan hasil standar deviasi 1 adalah 0,186 dan standar deviasi 2 adalah 0,599, kekuatan uji $95 \%$.

Hasil perhitungan besar sampel untuk penelitian ini sebanyak 17 orang. Untuk mengantisipasi kemungkinan drop out, diperlukan penambahan sampel sebanyak $10 \%$ dari jumlah sampel yaitu 1 orang sehingga jumlah sampel pada penelitian ini berumlah 18 orang. Adapun kriteria Inklusi sampel penelitian: a) Bayi prematur yang dirawat di ruang Perinatologi tanpa memperhatikan berat badan lahir; b) Bayi prematur yang dirawat di dalam inkubator; c) Ibu yang bersedia bayinya menjadi responden; d) Bayi prematur yang tidak dilakukan pembedahan dan tidak terdapat penyakit penyerta lainnya.

Data disajikan dalam mendistribusikan melalui analisis univariat dan analisis 
bivariate. Pengujian hipotesis penelitian menggunakan Uji Paired sampel t-test (Dahlan, 2013). Ho diterima bila $p \leq 0,05$.Kaji etik penelitian sudah dilakukan di Komite Etik Penelitian Kesehatan RSUD Dr. M. Yunus Bengkulu dengan No. 25/KEPKRSMY/IX/2020.

\section{HASIL}

Tabel 1.Distribusi Karakteristik Responden (Jenis Kelamin, Usia Gestasi, Berat Badan Lahir) di Ruang Perinatologi RSUD dr. M. Yunus Bengkulu

\begin{tabular}{|c|c|c|c|c|}
\hline Karateristik & Kelompok & & Frekuensi & Persentase (\%) \\
\hline \multirow[t]{4}{*}{ Jenis Kelamin } & Intervensi & Laki-Laki & 9 & 50.0 \\
\hline & & Perempuan & 9 & 50.0 \\
\hline & Kontrol & Laki-Laki & 9 & 50.0 \\
\hline & & Perempuan & 9 & 50.0 \\
\hline \multirow[t]{4}{*}{ Usia Gestasi } & Intervensi & $27-30$ Minggu & 13 & 72.2 \\
\hline & & 31 - 34 Minggu & 5 & 27.8 \\
\hline & Kontrol & 27-30 Minggu & 11 & 61.1 \\
\hline & & 31-34 Minggu & 7 & 38.9 \\
\hline \multirow[t]{4}{*}{ Berat Bayi Lahir } & Intervensi & $1500-2000$ gram & 13 & 72.2 \\
\hline & & 2050-2300 gram & 5 & 27.8 \\
\hline & Kontrol & $1600-2000$ gram & 8 & 44.4 \\
\hline & & 2010-2400 gram & 10 & 55.6 \\
\hline
\end{tabular}

Berdasarkan tabel diatas didapatkan hasil penelitian untuk jenis kelamin pada masingmasing variabel baik pada kelompok kontrol mauun intervensi adalah sebanyak 9 0rang $(50 \%)$ dengan jenis kelamin laki-laki dan sebanyak 9 orang $(50 \%)$ dengan jenis kelamin perempuan. Usia Gestasi pada kelompok kontrol adalah sebanyak 11 orang $(61,1 \%)$ dengan usia gestasi 27-30 minggu dan pada kelompok intervensi adalah sebanyak 13 orang $(72,2 \%)$ dengan usia gestasi 27-30 minggu. Berat badan bayi pada kelompok kontrol adalah sebanyak 8 orang $(44,4 \%)$ dengan berat bayi 100-2000 gram dan sebanyak 13 orang $(72,2 \%)$ dengan berat bayi 1500-2000 gram. 
Tabel 2. Distribusi Frekuensi Perubahan Fisiologis Bayi Prematur (Saturasi Oksigen, Frekuensi Nafas, Frekuensi Nadi) di Ruang Perinatologi RSUD dr. M. Yunus Bengkulu

\begin{tabular}{llcccccc}
\hline & Kelompok & Mean & Median & $\begin{array}{c}\text { Standar } \\
\text { Deviasi } \\
(\text { SD) }\end{array}$ & Terendah & Tertinggi & $95 \%$ CI \\
\hline $\begin{array}{l}\text { Saturasi } \\
\text { Oksigen }\end{array}$ & Intervensi & 98.17 & 98.50 & 1.618 & 95 & 100 & $97.36-98.97$ \\
& Kontrol & 96.22 & 96.00 & 2.365 & 91 & 100 & $95.05-97.40$ \\
\hline $\begin{array}{l}\text { Frekuensi } \\
\text { Nafas }\end{array}$ & Intervensi & 97.61 & 99.00 & 12.654 & 78 & 120 & $91.32-103.90$ \\
& Kontrol & 85.44 & 89.00 & 9.817 & 65 & 100 & $80.56-90.33$ \\
\hline $\begin{array}{l}\text { Frekuensi } \\
\text { Nadi }\end{array}$ & Intervensi & 110.50 & 109.00 & 18.118 & 80 & 140 & $101.49-119.51$ \\
& Kontrol & 97.44 & 102.50 & 19.820 & 60 & 126 & $87.59-107.30$ \\
\hline
\end{tabular}

Berdasarkan tabel diatas didapatkan nilai rata-rata saturasi oksigen pada kelompok kontrol adalah 96,22 dengan confidence interval 95,05 - 97,40 sedangkan pada kelompok intervensi didapatkan rata-rata saturasi oksigen adalah 98,17 dengan confidence interval 97,36 - 98,97. Nilai rata-rata frekuensi nafas pada kelompok kontrol adalah 85,44 dengan confidence interval 80,56 - 90,33 sedangkan pada kelompok intervensi didapatkan rata-rata frekuensi nafas adalah 97,61 dengan confidence interval 91,32 - 103,90. Nilai rata-rata frekuensi nadi pada kelompok kontrol adalah 97,44 dengan confidence interval 87,59 107,30 sedangkan pada kelompok intervensi didapatkan rata-rata frekuensi nadi adalah 110,50 dengan confidence interval 101,49 - 119,51.

Tabel 3. Pengaruh Nesting Terhadap Perubahan Fisiologis Bayi Prematur Di Ruang Perinatologi RSUD DR. M. Yunus Bengkulu

\begin{tabular}{llcccc}
\hline $\begin{array}{c}\text { Perubahan Fisiologis } \\
\text { Bayi Prematur }\end{array}$ & \multicolumn{1}{c}{ Kelompok } & Mean & $\begin{array}{c}\text { Standar Deviasi } \\
(\text { SD) }\end{array}$ & $\begin{array}{c}\text { Standar Error } \\
(\text { SE) }\end{array}$ & $P$ Value \\
\hline Saturasi Oksigen & Intervensi & 98.17 & 1.618 & 0.381 & 0.007 \\
& Kontrol & 96.22 & 2.365 & 0.558 & 0.003 \\
\hline Frekuensi Nafas & Intervensi & 97.61 & 12.654 & 2.983 & 2.314 \\
\hline Frekuensi Nadi & Kontrol & 85.44 & 9.817 & 4.270 & 0.047
\end{tabular}

Berdasarkan tabel diatas didapatkan hasil ada pengaruh nesting terhadap saturasi oksigen pada bayi prematur di Ruang Perinatologi RSUD DR. M. Yunus Bengkulu dengan $p$ 
value 0,007. Ada pengaruh nesting terhadap frekuensi nafas pada bayi prematur di Ruang Perinatologi RSUD DR. M. Yunus Bengkulu dengan $p$ value 0,003 dan ada pengaruh nesting terhadap frekuensi nadi pada bayi prematur di Ruang Perinatologi RSUD DR. M. Yunus Bengkulu dengan $p$ value 0,047.

\section{PEMBAHASAN}

\section{Pengaruh nesting terhadap perubahan fisiologis bayi premature di Ruang perinatology RSUD DR. M. Yunus Bengkulu}

Peneliti berasumsi adanya peningkatan saturasi oksigen pada kasus ini karena usia bayi yang relatif muda dibawah satu bulan berhubungan dengan masih adanya sisa fase akumulasi hemoglobin sampai dengan adanya pemberian intake nutrisi yang didapat oleh responden. Selain itu, faktor kenyamanan yang dialami bayi mampu menurunkan metabolisme tubuh yang pada akhirnya bisa meningkatkan saturasi oksigen. Hemoglobin berperan dalam mengikat oksigen dalam setiap molekulnya. Oleh sebab itu, bila kadar hemoglobin dalam darah kurang akan mempengaruhi saturasi oksigen dalam tubuh.

Hasil penelitian ini didukung oleh (Zen, 2018), menjelaskan bahwa ada pengaruh nesting terhadap peningkatan saturasi oksigen pada bayi prematur dengan $\mathrm{p}$ value $=0,000$. Hasil penelitian lainnya oleh(Asriyani, 2017), menjelaskan bahwa ada pengaruh yang bermakna nesting terhadap saturasi oksigen dengan $\mathrm{p}$ value $=0,000$. Hasil penelitian serupa juga dilakukan oleh(Bayuningsih, 2011), menjelaskan bahwa terdapat perbedaan bermakna saturasi oksigen sebelum dan sesudah penggunaan nesting pada bayi prematur dengan $\mathrm{p}$ value $=0,001$.

Hasil penelitian ini didukung oleh penelitian (Maher \& Elarousy, 2018), Denyut jantung neonatus rata-rata adalah 143,40 \pm 14,95 setelah bersarang dibandingkan dengan $157,57 \pm 15,88$ untuk neonatus kontrol. kelompok dan perbedaannya signifikan secara statistik. Selanjutnya rerata saturasi oksigen neonatus pada kelompok studi lebih tinggi daripada pada kelompok kontrol (97,43 \pm 1,47, 95,63 \pm 0,76 masing-masing) dan perbedaannya signifikan secara statistik. Selain itu, ditemukan bahwa 43,3\% neonatus kelompok studi dan $10 \%$ neonatus pada kelompok kontrol mengalami tidur nyenyak dan tidur nyenyak. perbedaan antara kedua kelompok signifikan secara statistik.

Hasil penelitian menunjukkan bahwa bayi prematur yang menjalani proses nesting menunjukkan perlambatan frekuensi pernafasan yang lebih signifikan dibandingkan kelompok pertama. Hal tersebut dapat dipengaruhi oleh kematangan organ bayi prematur yang semakin meningkat. Nesting dalam hal ini membantu mengkondisikan lingkungan bayi 
agar tetap kondusif sehingga energi yang dimilikinya dapat dimaksimalkan untuk mendukung tumbuh kembang bayi prematur sehingga lebih cepat dalam mencapai kondisi kesehatan yang optimal.

Penurunan frekuensi pernafasan ini karena bayi lebih tenang dan tidur lebih banyak saat bersarang. Ini juga menunjukkan penurunan tingkat stres bayi akibat perlambatan tingkat kortisol tubuh. Penelitian Mooncey et al menunjukkan bahwa penurunan kadar kortisol sebanyak $\pm 60 \%$ mempengaruhi area limbik korteks insular di otak, kemudian menghasilkan produksi oksitosin yang dapat menenangkan dan menstabilkan sistem kardiorespirasi. Saat bersarang, posisi bayi diubah agar tidak selalu dalam posisi terlentang yang dapat meningkatkan kompresi diafragma. Bayi diposisikan secara fleksibel sehingga dapat mengoptimalkan fungsi sistem pernafasan bayi (Zahra, et. Al., 2018).

Berdasarkan hasil observasi peneliti, meskipun bayi mendapatkan nesting namun disekitar lingkungan bayi masih ada stimulus yang menjadi stresor sepertihalnya kebisingan ruangan, beberapa prosedur medis dan tindakan keperawatan. Hasil analisis ini, tidak menutup kemungkinan kondisi ini menjadi sumber stres yang dapat meningkatkan saraf simpatis sehingga meningkatkan kontraktilitas jantung sehingga frekuensi nadipun akan meningkat.

Hasil penelitian ini didukung oleh penelitian (Ms. Ramya Poulose, 2015), dalam penelitiannya yang dilakukan pada 60 responden yang terbagi menjadi 30 responden kasus dan 30 responden kontrol. Hasil penelitiannya membuktikan bahwa BBLR yang diberikan nesting selama 9 jam per hari selama 5 hari menunjukan bahwa postur, kenyamanan dan parameter fisiologi (suhu aksila, nadi dan respirasi) menunjukan nilai yang signifikan yaitu $\mathrm{t}$ $=12,64$ yang berarti bahwa studi membuktikan nesting pada BBLR efektif dalam memperbaiki pertumbuhan, mununjukan kenyamanan serta menstabilkan parameter fisiologis seperti suhu, nadi dan pernapasan BBLR.

Hasil penelitian menunjukan terdapat peningkatan rerata suhu tubuh, saturasi oksigen dan frekuensi nadi pada BBLR setelah penggunaan nesting.Hasil penelitian terdapatperbedaan suhu tubuh, saturasi oksigen dan frekuensi nadi pada BBLR dengan masing -masing p value $<0,05$ (Saprudin \& Sari, 2018).

\section{KESIMPULAN}

Hasil penelitian dapat disimpulkan rata-rata saturasi oksigen pada kelompok kontrol adalah 96,22 sedangkan pada kelompok intervensi didapatkan rata-rata saturasi oksigen adalah 98,17 di Ruang Perinatologi RSUD dr. M. Yunus Bengkulu. Rata-rata frekuensi nafas 
pada kelompok kontrol adalah 85,44 edangkan pada kelompok intervensi didapatkan rata-rata frekuensi nafas adalah 97,61 di Ruang Perinatologi RSUD dr. M. Yunus Bengkulu. Rata-rata frekuensi nadi pada kelompok kontrol adalah 97,44 sedangkan pada kelompok intervensi didapatkan rata-rata frekuensi nadi adalah 110,50 di Ruang Perinatologi RSUD dr. M. Yunus Bengkulu. Ada pengaruh nesting terhadap saturasi oksigen pada bayi prematur di Ruang Perinatologi RSUD DR. M. Yunus Bengkulu dengan $p$ value 0,007.Ada pengaruh nesting terhadap frekuensi nafas pada bayi prematur di Ruang Perinatologi RSUD DR. M. Yunus Bengkulu dengan $p$ value 0,003.Ada pengaruh nesting terhadap frekuensi nadi pada bayi prematur di Ruang Perinatologi RSUD DR. M. Yunus Bengkulu dengan $p$ value 0,047.

\section{UCAPAN TERIMA KASIH}

Peneliti mengucapkan terima kasih kepada Kementerian Riset dan Teknologi / Badan Riset dan Inovasi Nasional Republik Indonesia (Kemenristek/BRIN) yang telah mendanai Penelitian skema Dosen Pemula. Direktur RSUD Dr. M. Yunus Bengkulu yang sudah memberikan fasilitas selama proses Penelitian. Yayasan Persada Raflesia dan Ketua STIKES Bhakti Husada Bengkulu.

\section{DAFTAR PUSTAKA}

Aita dan Snider. L. (2003). The Art of Developmental Care in the NICU : A Concept Analysis Journal of Advanced Nursing, 41 ( 3), 223-232

Altimier.L. (2011). Mother and Child Integrative Developmental Care Model : A Simple Approach to a Complex Population. Newborn \& Infant, Nursing Review, 11 (3),105108

Andhini, N. F. (2017). Journal of Chemical Information and Modeling, 53(9), 1689-1699.

Asriyani, A. F. nurhiidayah ikeu; marddhiyah ai; hendrawati sri; maryam nenden nur. (2017). Volume 4 | Nomor 2 | Desember 2017. Jurnal Keperawatan Aisyiyah, 4(6), 33-39.

Bayuningsih, R. (2011). Efektivitas Penggunaan Nesting dan Poisi Prone terhadap Saturasi Oksigen dan Frekuensi nadi pada bayi Prematur di RSUD Bekasi. Jurnal Kesehatan Bakti Tunas Husada, 17, 357-374.

Dharma, Kusuma Kelana. (2011).Metodologi Penelitian Keperawatan : Panduan Melaksanakan dan Menerapkan Hasil Penelitian, Jakarta, Trans InfoMedia

Krisnadi, dkk. 2009. Prematuritas. Bandung: Refika Aditama.

Maher, G., \& Elarousy, W. (2018). Nursing and Health Care Research Effect of Nested and Swaddled Prone Positioning on Sleep and Physiological Parameters of Low Birth Weight Neonates. 01(02), 1-9.

Ms. Ramya Poulose. (2015). Effect of Nesting on Posture Discomfort and Physiological\nParameters of Low Birth Weight Infants\n. IOSR Journal of Nursing and Health Science (IOSR-JNHS) , 4(1), 46-50. https://doi.org/10.9790/1959-04114650 
Notoatmodjo.(2014). Metodologi Penelitian Kesehatan.Jakarta : PT. Rineka Cipta.

Prawiroharjo S. (2012). Ilmu kebidanan, Edisi Tiga Cetakan Keenam. Jakarta: YBP-SP.

Saprudin, N., \& Sari, I. K. (2018). Pengaruh Penggunaan Nesting Terhadap Perubahan Di Kota Cirebon. Jurnal Ilmu Kesehatan Bhakti Husada, 09(02), 67-77.

SDKI. (2012). On http://www.menegpp.go.id/aplikasidata/index/php?option.com diunduh tanggal 12 Agustus 2019.

Sulistriani, D., Berliana, S. M. (2016). Faktor-Faktor yang Memengaruhi Kelahiran Prematur di Indonesia : Analisis Data Riskesdas 2013. E-Journal WIDYA Kesehatan dan Lingkungan, 1(2), 109-112

WHO, 2012. Born Too Soon: The Global Action Report on Preterm Birth,Geneva: WHO, 2012.

Zen, D. (2018). Pengaruh Nesting Terhadap Perubahan Fisiologis Dan Perilaku Bayi Prematur Di Perinatologi Rumah Sakit Umum Daerah Tasikmalaya. Jurnal Kesehatan Bakti Tunas Husada: Jurnal Ilmu-Ilmu Keperawatan, Analis Kesehatan Dan Farmasi, 17(2), 357. https://doi.org/10.36465/jkbth.v17i2.262 